\title{
Cervical human papillomavirus prevalence and genotype distribution among hybrid capture 2 positive women 15 to 64 years of age in the Gurage zone, rural Ethiopia
}

\author{
Sami-Ramzi Leyh-Bannurah', Christof Prugger ${ }^{2,3}$, Maurits NC de Koning ${ }^{4}$, Hartmut Goette ${ }^{5}$ and Ralph J Lellé ${ }^{*}$
}

\begin{abstract}
Background: Human papillomavirus (HPV) infection is a prerequisite of cervical cancer, the leading cause of cancer mortality in Ethiopian women today. Data on Ethiopian cervical HPV prevalence and genotype distribution are rare, but essential as pre-vaccine baseline data to monitor changes after initiating HPV vaccination. The objectives of this study were to assess the cervical HPV prevalence, genotype distribution and associated correlates among female hospital outpatients in rural Ethiopia.
\end{abstract}

Methods: We examined a consecutive sample of 537 women 15-64 years of age in rural Ethiopia between November and December 2006. Screening for low risk (LR) and high-risk (HR) cervical HPV infection was performed and HR positive samples were genotyped with a GP5+/6 + - and SPF10-primer based system.

Results: The age-standardized prevalence of HPV, HPV HR and HPV LR infection was 17.3\% (95\% Cl 14.1-20.5), 15.8\% (95\% Cl 12.7-18.9) and 3.9\% (95\% Cl 2.3-5.6), respectively. Among HC2 HPV HR positive infections ( $\mathrm{n}=86)$, the most common genotype was HPV 16 (24.4\%), followed by 52 (11.6\%), 56 (10.5\%) and 31 (10.5\%). Non-married relationship and widowhood, increasing number of lifetime sexual partners, human immunodeficiency virus infection and non-traditional housing type, but not age, were significantly associated with HR HPV infection.

Conclusions: These results on cervical HPV prevalence and genotype distribution may serve as baseline data in evaluating the impact of future HPV vaccination programmes in rural Ethiopia.

Keywords: Papillomavirus infections, Cervix uteri, Ethiopia, DNA probes, HPV, Epidemiology, Risk factors, Sub-Sahara Africa

\section{Background}

In the year 2012, estimates of the worldwide number of cervical cancer cases and deaths amounted to 527,624 and 265,653, respectively [1]. More than $80 \%$ of global invasive cervical cancer (ICC) cases occur in developing countries and come with a higher mortality/incidence ratio [2]. National cervical cancer screening only covers less than $1 \%$ of the female population in Ethiopia, where ICC is associated with the highest cancer mortality among women [2]. For 2012, the estimated agestandardized incidence and mortality rates were 26.4

\footnotetext{
* Correspondence: office@lellenet.de

'Department of Gynecology and Obstetrics, University Hospital of Muenster, Muenster, Germany

Full list of author information is available at the end of the article
}

and 18.4 per 100,000 Ethiopian women, respectively, corresponding to a 4- and 9-times higher incidence and mortality rate than in Western Europe [1].

Persistent high-risk (HR) HPV infection is a prerequisite for the development of cervical cancer [3]. Because nationwide cervical cancer screening is rarely established in countries with limited resources, HPV vaccination programmes may be an alternative and cost-effective option in these settings [4]. However, there is great heterogeneity with regard to the country-specific HPV prevalence, type-specific distribution and associated characteristics across age groups that must be considered prior to introducing HPV vaccination $[5,6]$. Moreover, such baseline data are very limited in Ethiopia, but 
would facilitate consecutive monitoring of any changes in HPV type-specific distributions by HPV target evasion that could possibly limit the effect of HPV vaccination $[7,8]$.

In the present study, we report on the prevalence of cervical HPV infection, the distribution of HPV genotypes and determinants of HPV HR infection among hospital outpatients from rural Ethiopia.

\section{Methods}

\section{Study population}

Attat Hospital is located in the rural Gurage zone, central Ethiopia. The estimated catchment area of the hospital comprises around 1 million inhabitants [9]. Between November and December 2006, a consecutive sample of 537 women 15 to 64 years of age who visited the outpatient department were recruited with the aim of including 50 women from each 5-year age group. Main causes of outpatient visits were gynaecological diseases, perinatal care, and respiratory tract and gastrointestinal infections.
Women were included if they reported to have been sexually active. Exclusion criteria were a history of hysterectomy, presence of conisation and physical or mental inability to attend the interview and pelvic examination. A total of 4 patients refused participation. At enrolment, all women provided written informed consent.

\section{Data collection}

One senior gynaecologist performed all gynaecological examinations, and the cervix could be visualized in all women using a Cusco speculum. Cervical samples were collected using a swab (digene Cervical Sampler, Qiagen, Hilden, Germany) and stored at $-10^{\circ} \mathrm{C}$ for later HPV detection and genotyping. The questionnaire was translated into Amharic and back to English to ensure equivalence. It covered sociodemographic, sexual and reproductive characteristics, and lifestyle habits. Among 235 patients (43.8\%) who were not able to report their age or date of birth, age was estimated by the senior gynaecologist in consensus with the medical nurse.

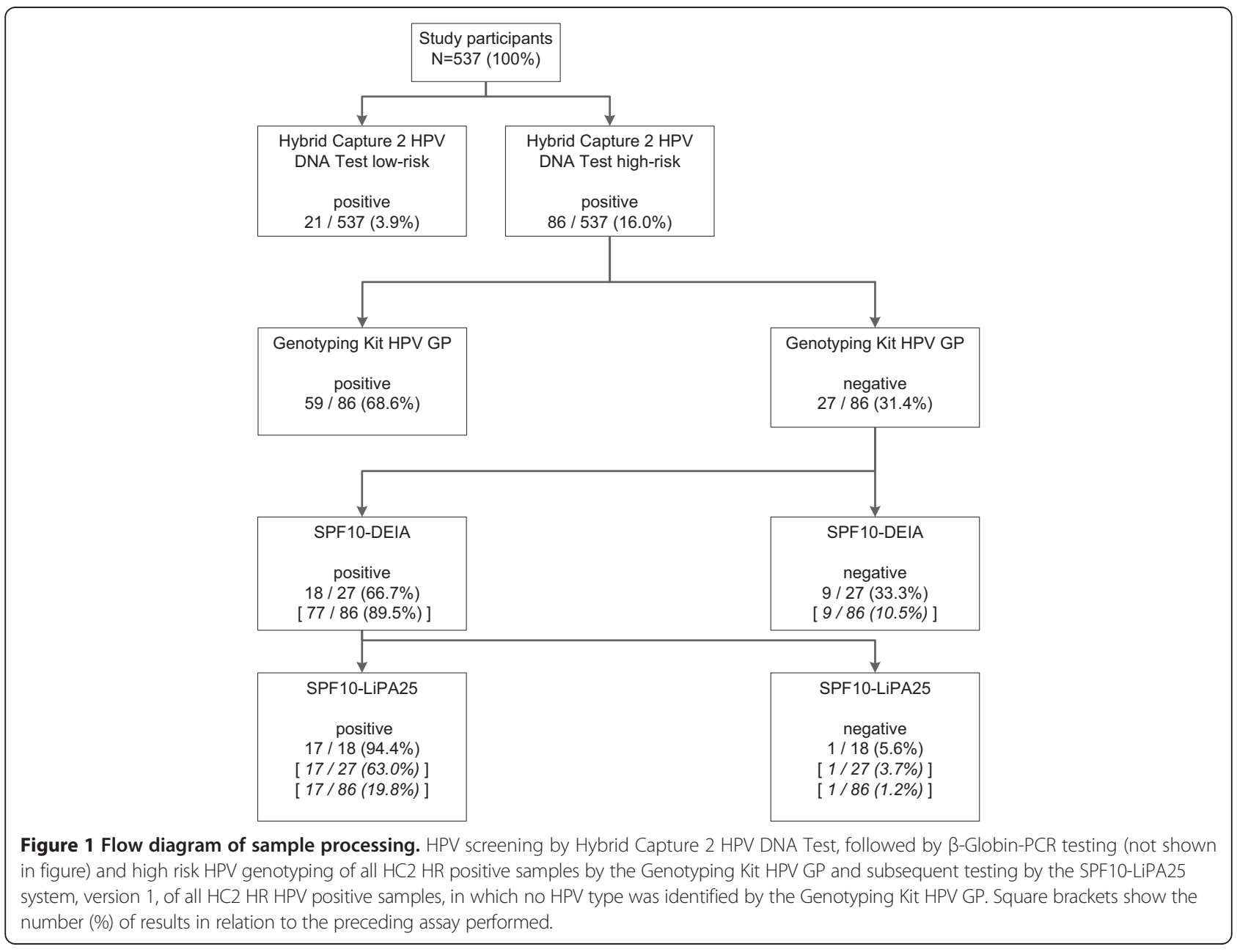




\section{HPV screening}

The digene Hybrid Capture 2 HPV DNA Test ([HC2] Qiagen, Hilden, Germany) was performed according to manufacturer's specifications at the Cytopathology Laboratory of the Department of Gynaecology and Obstetrics, University of Muenster, Germany, as described previously [10]. Using the HR HPV probe, 13 HR HPV types (16/ 18/ $31 / 33 / 35 / 39 / 45 / 51 / 52 / 56 / 58 / 59 / 68$ ) can be collectively detected without identifying the HPV genotype. Similarly, five low-risk (LR) HPV types (6/ 11/ 42/ 43/44) can be detected with the LR HPV probe.

All HC2 HR HPV positive samples were further analysed at DDL Diagnostic Laboratory (Rijswijk, Netherlands). An overview of the HPV detection and consecutive HPV genotyping algorithm is shown in Figure 1.

\section{HPV genotyping}

The quality of the isolated DNA was checked by amplifying a 268 base pair fragment from the $ß$-globin gene with primers PC04 and GH20 [11]. First, the Genotyping Kit HPV GP (Diassay BV, Rijswijk, The Netherlands) was used according to the instructions of the manufacturer [12]. This kit identifies 14 HR genotypes (16/ 18/ $31 / 33 / 35 / 39 / 45 / 51 / 52 / 56 / 58 / 59 / 66 / 68$ with subtype $68 \mathrm{a})$ and 4 possible HR HPV types (26/53/73/ 82 with subtypes IS39 and MM4). Second, in HC2 HR HPV positive samples in which no HPV type was identified by the Genotyping Kit HPV GP ( $n=27$; Figure 1), the highly sensitive SPF10-LiPA25, version 1 system (Labo Bio-medical Products, Rijswijk, The Netherlands) was used for further evaluation of HPV genotypes as described previously [13]. The SPF10-DNA Enzyme Immuno Assay (DEIA) allows a pooled broad spectrum HPV detection of more than 54 HPV types and the SPF10-line probe assay (LiPA) enables subsequent genotyping of 25 different LR and HR HPV genotypes (6/ 11/ 16/ 18/31/33/34/35/ 39/40/42/43/44/45/51/52/53/ 54/ 56/ 58/ 59/ 66/ "68/73"/ 70/74). Genotypes 68 and 73 cannot be discriminated by the LiPA [13].

\section{Statistical analysis}

Descriptive statistics are presented as numbers (\%) and median (interquartile range, IQR). Prevalence estimates were age standardised using the world standard population as reported by Doll et al. [14]. Associations of patient characteristics with HPV HR infection were assessed using logistic regression analysis to estimate odds ratios (ORs) with 95\% confidence intervals (CI). A multivariable model was fitted using backward selection among variables identified in univariate analyses using an entry threshold of $\mathrm{p}<0.10$. All tests were two-sided and an alpha level of 0.05 was chosen to indicate statistical significance. Analyses were performed using SPSS 18.0.3 (IBM, New York, USA).

\section{Results}

Patient characteristics

Median age at onset of menstrual bleeding was 13 years (IQR 13-14), age at sexual debut and first pregnancy were both at 18 years (IQRs 15-20 and 15-21, respectively). The median number of life births reported was 4 (IQR 2-7).

Overall, 391 (72.8\%) women were in a monogynous marriage and 102 (19.0\%) were widowed. Median length of partnership was 9 years (IQR 3-19). The median number of lifetime sexual partners was 1 (IQR 1-1), with 123 (22.9\%) women having more than one lifetime sexual partner. 404 (75.2\%) patients denied to have ever used any contraceptive method.

\section{Frequency of HPV infections}

Figure 1 shows the flow chart of sample processing. The frequency of HPV HR and LR infection was $16.0 \%$ and 3.9\%, respectively. A HPV HR and LR co-infection was present in $13(2.4 \%)$ women. Thus, a total of $94(17.5 \%)$ women were classified as HPV positive by HC2. The age-standardized prevalence of HPV, HR HPV and LR HPV infection amounted to $17.3 \%$ (95\% CI 14.1-20.5), 15.8\% (95\% CI 12.7-18.9) and 3.9\% (95\% CI 2.3-5.6), respectively.

Figure 2 shows the frequency of HPV, HR HPV and LR HPV infections by 10-year age groups. Neither the frequency of HPV, nor the one of HR HPV and LR HPV infections showed a significant age pattern ( $\mathrm{p}$ for trend $=$ $0.473,0.566$ and 0.571 , respectively).

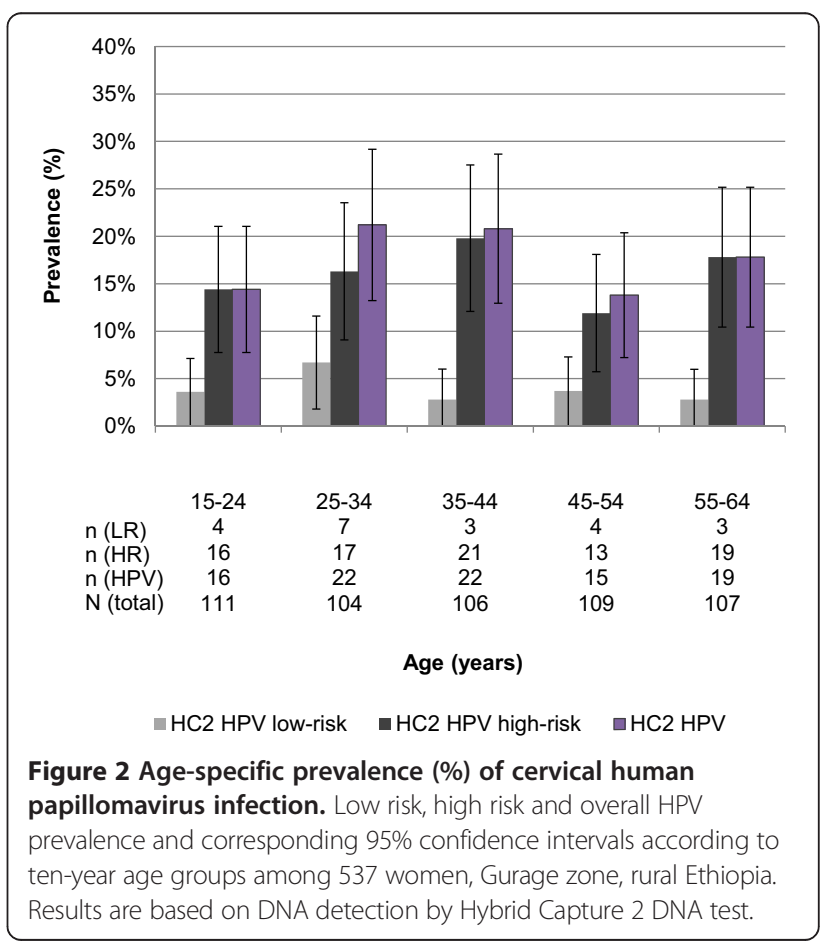




\section{HPV genotypes}

All 86 HC2 HR HPV positive samples were used for subsequent HPV genotyping. As shown in Figure 1, primary testing by the Genotyping Kit HPV GP identified the HPV type in 59 samples (68.6\%). Further testing with the highly sensitive SPF10-LiPA25, version 1, additionally identified 15 HR HPV (partially with HPV coinfections) and two LR mono-infections. Despite being SPF10 DEIA positive, one sample remained LiPA negative, indicating the presence of another type than the 25 HPV types included on the LiPA. An exact genotype could not be identified.

Table 1 presents the cervical HPV genotype distribution identified by Genotyping Kit HPV GP and SPF10-LiPA25 system, version 1, among HC2 HR HPV positive infections $(n=86)$. Table 2 allows discriminating between the genotyping results of both PCR assays. Among HC2 HR HPV positive infections $(\mathrm{n}=86)$, the most common genotype was HPV 16 (24.4\%), followed by 52 (11.6\%), 56 (10.5\%), 31 (10.5\%), 51 (7.0\%), 35 and 39 (both 5.8\%), 45 and 68 (both 4.7\%), and 18 (3.5\%). Overall, 17 different HR and 3 different LR HPV genotypes were identified, amounting to a total of $92 \mathrm{HR}$ or LR infections. In this group, 49 (53.3\%), 19 (20.7\%) and 12 (13.0\%) HPV infections were attributed to species $\alpha 9$ (HPV 16, 31, 33, 35, 52, 58, 67), $\alpha 7$ (HPV 18, 39, 45, 59, 68, 70) and $\alpha 6$ (HPV $53,56,66)$, respectively, based on their phylogenetic classification [15]. Furthermore, in this group, 24 (26.1\%) and $52(56.5 \%)$ HPV infections would be targeted by a current bivalent (types 16 and 18) and an impending next generation nonavalent (types 6, 11, 16, 18, 31, 33, 45, 52 and 58) HPV vaccine, respectively [16].

\section{Univariate and multivariable associations with HPV HR infection}

In univariate analyses for the association with HPV HR infection, the following patient characteristics did not reach the threshold of $\mathrm{p}<0.10$ : religion, educational level of the women and their partner, patient's income, age at menarche, parity, current pregnancy, female circumcision,

Table 1 Cervical HPV genotype distribution and phylogenetic classification among HC2 high risk positive women, Gurage zone, rural Ethiopia

\begin{tabular}{|c|c|c|c|c|c|}
\hline \multirow{2}{*}{ HPV genotypes* } & \multicolumn{3}{|c|}{ Number of HPV infections } & \multirow{2}{*}{$\frac{\mathrm{n}=86}{\text { Percent }}$} & \multirow{2}{*}{$\begin{array}{l}\text { Phylogenetic } \\
\text { classification } \\
\text { Species }\end{array}$} \\
\hline & Single & Multiple** & Total & & \\
\hline $11^{\mathrm{a}}$ & 1 & 0 & 1 & 1.2 & $a 10$ \\
\hline 16 & 16 & 5 & 21 & 24.4 & a9 \\
\hline 18 & 1 & 2 & 3 & 3.5 & a7 \\
\hline 31 & 6 & 3 & 9 & 10.5 & a9 \\
\hline 33 & 1 & 1 & 2 & 2.3 & a9 \\
\hline 35 & 4 & 1 & 5 & 5.8 & a9 \\
\hline 39 & 4 & 1 & 5 & 5.8 & a7 \\
\hline $43^{\mathrm{a}}$ & 0 & 1 & 1 & 1.2 & a8 \\
\hline 45 & 3 & 1 & 4 & 4.7 & a7 \\
\hline 51 & 5 & 1 & 6 & 7.0 & a5 \\
\hline 52 & 7 & 3 & 10 & 11.6 & a9 \\
\hline 53 & 1 & 0 & 1 & 1.2 & $a 6$ \\
\hline 56 & 5 & 4 & 9 & 10.5 & $a 6$ \\
\hline 58 & 2 & 0 & 2 & 2.3 & a9 \\
\hline 59 & 1 & 0 & 1 & 1.2 & a7 \\
\hline 66 & 2 & 0 & 2 & 2.3 & $a 6$ \\
\hline 68 & 2 & 2 & 4 & 4.7 & a7 \\
\hline $70^{\mathrm{a}}$ & 1 & 1 & 2 & 2.3 & a7 \\
\hline 73 & 0 & 1 & 1 & 1.2 & a11 \\
\hline 82 & 1 & 0 & 1 & 1.2 & a5 \\
\hline $68 / 73^{b}$ & 2 & 0 & 2 & 2.3 & $a 7$ or a11 \\
\hline
\end{tabular}

*Genotypes identified in HC2 high risk positive infections by Genotyping Kit HPV GP and SPF10-LiPA25, version 1.

**Only HPV high risk co-infections were considered.

${ }^{\mathrm{a}} \mathrm{HPV}$ low-risk genotype.

${ }^{\mathrm{b}}$ Discrimination between HPV genotypes 68 and 73 is not possible with SPF10-LiPA25 system, version 1. 
Table 2 Cervical HPV infection stratified by results of Genotyping Kit HPV GP and SPF10-LiPA25, version 1 among HC2 high risk positive women, Gurage zone, rural Ethiopia

\begin{tabular}{|c|c|c|c|}
\hline \multirow[t]{2}{*}{ HPV infection } & Total & $\begin{array}{l}\text { HPV genotype } \\
\text { by genotyping } \\
\text { Kit HPV GP }\end{array}$ & $\begin{array}{c}\text { HPV genotype } \\
\text { by SPF10-LiPA25, } \\
\text { ver. } 1^{*}\end{array}$ \\
\hline & $n$ & $\mathrm{n}$ & $\mathrm{n}$ \\
\hline $11^{a}$ & 1 & & 1 \\
\hline 16 & 16 & 16 & \\
\hline 18 & 1 & 1 & \\
\hline 31 & 6 & 6 & \\
\hline 33 & 1 & 1 & \\
\hline 35 & 4 & 4 & \\
\hline 39 & 4 & 2 & 2 \\
\hline 45 & 2 & 2 & \\
\hline 51 & 5 & 1 & 4 \\
\hline 52 & 7 & 4 & 3 \\
\hline 53 & 1 & & 1 \\
\hline 56 & 5 & 5 & \\
\hline 58 & 2 & 1 & 1 \\
\hline 59 & 1 & 1 & \\
\hline 66 & 2 & 2 & \\
\hline 68 & 2 & 2 & \\
\hline $70^{\mathrm{a}}$ & 1 & & 1 \\
\hline 82 & 1 & 1 & \\
\hline $68 / 73^{b}$ & 2 & & 2 \\
\hline 16,56 & 2 & 2 & \\
\hline 18,52 & 1 & 1 & \\
\hline 18,56 & 1 & 1 & \\
\hline 31,56 & 1 & 1 & \\
\hline 31,68 & 1 & 1 & \\
\hline 39,73 & 1 & 1 & \\
\hline $45,70^{\mathrm{a}}$ & 1 & & 1 \\
\hline $16,31,35$ & 1 & 1 & \\
\hline $16,33,68$ & 1 & 1 & \\
\hline $16,45,52$ & 1 & 1 & \\
\hline $43^{\mathrm{a}}, 51,52$ & 1 & & 1 \\
\hline
\end{tabular}

*Only samples negative by Genotyping Kit HPV GP were tested by SPF10-LiPA25, version 1.

${ }^{a} \mathrm{HPV}$ low-risk genotype.

${ }^{\mathrm{b}}$ Discrimination between HPV genotypes 68 and 73 is not possible with SPF10-LiPA25, version 1.

alcohol consumption and khat chewing (Additional file 1). Table 3 presents univariate and multivariable associations with HPV HR infection of the remaining patient characteristics under investigation: non-married relationship and widowhood, increasing number of lifetime sexual partners, human immunodeficiency virus infection (HIV) and non- traditional housing type were independently associated with HR HPV infection.

\section{Discussion}

The present study reports on the prevalence of cervical HPV infection, the distribution of HPV genotypes and determinants of HPV HR infection in rural Ethiopia. Our study reveals several important findings.

\section{HPV prevalence}

We observed an age-standardised prevalence of HPV infection of $17.3 \%$ and an age-standardised prevalence of HPV HR infection of $15.8 \%$. A review by Smith et al. reported great variations in the HPV prevalence across African countries ranging from $12 \%$ to $46 \%$ [17]. Specifically, studies from the Sub-Saharan African countries Nigeria [18], Uganda [19] and Mozambique [20] reported HPV HR frequencies of $14.7 \%, 19.2 \%$ and $40.0 \%$, respectively. In comparison, HR HPV prevalence estimates for developed countries in Western Europe range from $9.4 \%$ to $12.1 \%$ [21]. Thus, our study results indicate that the HPV HR prevalence in rural Ethiopia is consistent with reports from Sub-Saharan Africa, but almost twice as high as in most Western European countries.

No significant age pattern was observed, despite including the rarely reported age interval of 15 years up to 64 years in our study. However, instead, there was a rather high HPV HR prevalence of at least $10 \%$ in each 10-year age group. Worldwide and African studies reported heterogeneous age patterns: HPV HR prevalence decreasing with age $[5,19,22]$, showing an U-shaped curve $[22,23]$ or being consistently high across all age groups [5,20,24]. The latter is the case in the present study, possibly indicating a lifespan HPV persistence and/or a reacquisition with increasing age due to changing sexual behaviour and age-related changes of mucosal biology and immune competence [5,23]. This is also consistent with our result on widowhood, which increased with age, as a correlate for HR HPV infection.

\section{HPV genotypes}

The 5 most common HPV genotypes in our study sample were HPV 16 (24.4\%), followed by 52 (11.6\%), 56 (10.5\%) and 31 (10.5\%) and 51 (7.0\%). Among women with normal cytology, HPV types 16, 18, 31, 58, 52 and $52,16,18,53$, 66 are estimated to be the most common worldwide and in Eastern Africa, respectively [22]. Our study reveals HPV genotypes 16 and 52 as predominant genotypes in Ethiopia. HPV 16 has the highest carcinogenic potential and is targeted by current HPV vaccines [15]. Nonetheless, as expected, also oncogenic HR HPV genotypes were identified, which are not targeted by current and advertised polyvalent vaccines [16]. However, HPV vaccination remains a promising approach in Ethiopia for multiple 
Table 3 Odds ratios for HR HPV positivity and corresponding 95\% Cls by selected characteristics, Gurage zone, rural Ethiopia

\begin{tabular}{|c|c|c|c|c|c|c|c|c|}
\hline & \multicolumn{2}{|c|}{ HC2 HR positivity } & \multicolumn{3}{|c|}{ Univariable } & \multicolumn{3}{|c|}{ Multivariable } \\
\hline & $\mathrm{n} /$ total & $\%$ & $\overline{O R}$ & $95 \% \mathrm{Cl}$ & p-value & $\overline{A O R}$ & $95 \% \mathrm{Cl}$ & $\mathrm{p}$-value \\
\hline \multicolumn{9}{|l|}{ Age interval } \\
\hline $15-24$ & $16 / 111$ & 14 & 1.00 & & 0.572 & & & \\
\hline $25-34$ & $17 / 104$ & 16 & 1.16 & $(0.55-2.44)$ & 0.695 & & & \\
\hline $35-44$ & $21 / 106$ & 20 & 1.47 & $(0.72-2.99)$ & 0.292 & & & \\
\hline $45-54$ & $13 / 109$ & 12 & 0.80 & $(0.37-1.76)$ & 0.586 & & & \\
\hline $55-64$ & $19 / 107$ & 18 & 1.28 & $(0.62-2.65)$ & 0.502 & & & \\
\hline \multicolumn{9}{|l|}{ Marital status } \\
\hline Married, monogynous & $51 / 391$ & 13 & 1.00 & & 0.021 & 1.00 & & 0.047 \\
\hline Married, polygynous & $4 / 18$ & 22 & 1.91 & $(0.60-6.01)$ & 0.272 & 1.26 & $(0.35-4.57)$ & 0.728 \\
\hline With Partner (not married) & $3 / 6$ & 50 & 6.67 & $(1.31-33.93)$ & 0.022 & 7.22 & $(1.37-38.10)$ & 0.020 \\
\hline Divorced or separated & $4 / 20$ & 20 & 1.67 & $(0.54-5.18)$ & 0.378 & 0.66 & $(0.16-2.69)$ & 0.561 \\
\hline Widowed & $24 / 102$ & 24 & 2.05 & $(1.19-3.53)$ & 0.010 & 1.85 & $(1.01-3.41)$ & 0.047 \\
\hline \multicolumn{9}{|l|}{ Lifetime number of sexual partners } \\
\hline 1 & $55 / 414$ & 13 & 1.00 & & 0.004 & 1.00 & & 0.011 \\
\hline 2 & $25 / 106$ & 24 & 2.01 & $(1.18-3.43)$ & 0.010 & 1.83 & $(1.03-3.23)$ & 0.039 \\
\hline$\geq 3$ & $6 / 17$ & 35 & 3.56 & $(1.27-10.02)$ & 0.016 & 3.94 & $(1.33-11.65)$ & 0.013 \\
\hline \multicolumn{9}{|l|}{ History of STD } \\
\hline Never & $71 / 502$ & 14 & 1.00 & & $<0.001$ & 1.00 & & 0.002 \\
\hline Other STD than HIV* & $4 / 14$ & 29 & 2.43 & $(0.74-7.95)$ & 0.143 & 1.95 & $(0.57-6.69)$ & 0.291 \\
\hline HIV & $9 / 12$ & 75 & 18.21 & $(4.81-68.90)$ & $<0.001$ & 13.59 & $(3.25-56.89)$ & $<0.001$ \\
\hline Unknown/unsure & $2 / 9$ & 22 & 1.73 & $(0.35-8.52)$ & 0.498 & 2.47 & $(0.49-12.45)$ & 0.274 \\
\hline \multicolumn{9}{|l|}{ Main house } \\
\hline Traditional thatched house (gojo) & $60 / 429$ & 14 & 1.00 & & & 1.00 & & \\
\hline Other & $26 / 108$ & 24 & 1.95 & $(1.16-3.28)$ & 0.012 & 1.98 & $(1.10-3.57)$ & 0.022 \\
\hline
\end{tabular}

Results are based on high risk HPV DNA detection by Hybrid Capture 2 DNA test and presented among 537 women.

*Other STDs reported were gonorrhea, syphilis and chlamydia infection; $95 \% \mathrm{Cl}=95 \%$ confidence interval; $\mathrm{AOR}=$ adjusted odds ratio; $\mathrm{HC} 2=\mathrm{hybrid}$ capture $2 \mathrm{HPV}$ test; HIV = human immunodeficiency virus; $\mathrm{OR}=$ odds ratio; STD = sexually transmitted disease.

reasons. First, vaccines may provide cross-protection against non-vaccine type HPVs [25,26]. Second, many oncogenic HPV infections that evade the vaccine target range are transient and do not reach relevant stages of cervical carcinogenesis [27]. Third, specifically in settings like Ethiopia with very limited resources and poor cervical cancer screening coverage, HPV vaccination may represent a definitive prevention strategy. Our data on Ethiopian HPV prevalence and genotype distribution would represent a first step to build baseline data enabling to monitor dynamics in HPV genotype distribution as an effect of HPV vaccination that can be registered earlier than changes in (pre)cancerous cervical lesions, which naturally can take decades. However, Ethiopian data collection on baseline HPV type prevalence in ICC patients also remains a priority so that long term HPV vaccine efficacy can be finally evaluated.
In our study, HPV types 18, 53 and 66 were not corroborated as other common types in Eastern Africa, but were rather rare [22]. First, this might be attributed to the low share of African studies in worldwide reviews, i.e. only $3.9 \%$ in a meta-analysis by de Sanjose et al. [22] and thus limited data from African regions. Second, HPV results from various populations often differ by age ranges, settings and HPV assays used [28], which makes comparisons difficult. However, our study includes a wide age range (15-64 years), a balanced age distribution of at least 50 participants per 5-year age group and established $\mathrm{HC} 2$ HPV screening with a sophisticated two-step genotyping algorithm.

\section{Correlates of HC2 HR HPV infection}

Our analyses revealed that non-married relationship and widowhood, increasing number of lifetime sexual partners, 
human immunodeficiency virus infection (HIV) and non-traditional housing type were independently associated with HR HPV infection. These results are in line with previous reports showing that marital status, number of lifetime sexual partners and history of STDs, particularly HIV, are established risk factors for HR HPV infection $[3,19,28,29]$.

A housing type other than gojo, presumably depicting a higher socioeconomic status or an urban living area, was positively associated with HPV HR infection. Conversely to this finding, many studies have described an increased risk of HPV infection with lower socioeconomic status [30]. Possibly, living in rural areas can be beneficial with regard to female health status in our study setting. Supporting this theory is a 11-fold difference in HIV prevalence between rural and urban areas in Ethiopia (0.7\% versus $7.7 \%$, respectively) [31]. Neither parity nor age at first pregnancy nor use of oral contraceptives was significantly associated with HPV HR infection. These results are consistent with a metaanalysis by the International Agency on Research of Cancer [32].

\section{Sample testing}

In our study, primary screening was performed with $\mathrm{HC} 2$ because of high clinical sensitivity and specificity [33]. The occurrence of discordant results in our assay algorithm (i.e., HC2 positive with no HR HPV identified) may be attributable to false positive results with $\mathrm{HC} 2$ as exemplified by the 2 LR HPV mono-infections [34-36]. This would explain negative results in the subsequent Genotyping Kit HPV GP. Another possible explanation for a discordant result could be a sequence variation in the L1 target area, disrupting the GP5+/6 + - PCR target [37]. Because of the very high analytical sensitivity, we used the SPF10-LiPA25, version 1, for discrepancy analysis between the Genotyping Kit HPV GP and HC2 $[13,34]$, resulting in additional $17 / 27$ (63.0\%) genotyped samples. This may be related to the superior analytical sensitivity of the SPF10-LiPA25, version 1, compared to GP5+/6 + -primer based assays [13].

\section{Limitations and strengths}

Our study has certain limitations. First, patients were recruited in the single setting of Attat hospital and morbidity may be higher than in the general population. However, representative Ethiopian data are currently lacking, making our report the most comprehensive on HPV prevalence in Ethiopia yet. Second, no cytological evaluation was performed that would allow further sample stratification. However, this study focussed on HPV DNA testing in order to assess the burden of HPV infection and build baseline data prior to the implementation of HPV vaccination programmes to allow monitoring eventual changes in HPV prevalence and genotype distribution.

Third, the restriction of HPV genotyping to HC2 HR positive samples might have led to a bias in HPV type distribution and presentation.

\section{Perspectives}

Health economic models for evaluating the potential benefit of implementing HPV vaccination programs indicate that such interventions may be very cost-effective in Eastern Africa [4]. Challenges in the implementation must be considered, such as vaccine delivery (e.g. through health centers and schools), vaccine effect monitoring (e.g. sampling method, laboratory infrastructure, means of registration) and a vast cultural and regional diversity within Ethiopia. Corresponding analyses for Ethiopia are currently lacking and should thus be conducted before HPV vaccine delivery can finally be advocated. If Ethiopian large-scale introduction of HPV vaccination is envisaged, our data on the HPV genotype distribution would enable monitoring associated benefits and harms in rural settings.

\section{Conclusion}

Our results show a high frequency of at least 10\% HPV HR infection across all age groups, which is an important risk factor for cervical cancer development. The predominant HPV genotype that is already targeted in current HPV vaccination was 16 (24.4\%). For future use of HPV vaccines, our study provides the first share of important baseline data that would enable monitoring of interim HPV vaccination effects, such as changes in HPV prevalence and genotype distribution.

\section{Ethical approval}

The ethics committee of the Medical Association Westfalen-Lippe and the Medical Faculty of the University of Muenster, Germany, approved the study.

\section{Additional file}

Additional file 1: Odds ratios for HR HPV positivity and corresponding $95 \%$ Cls by remaining characteristics, Gurage zone, Ethiopia. The characteristics shown did not reach the threshold level for multivariable analysis.

\section{Abbreviations}

Cl: Confidence interval; DEIA: DNA enzyme immuno assay; HC2: Hybrid capture 2 HPV DNA test; HR: High risk; HPV: Human papillomavirus; ICC: Invasive cervical cancer; LR: Low risk; LiPA: Line probe assay; STD: Sexually transmitted disease.

\section{Competing interests}

The authors declare that they have no competing interests. 


\section{Authors' contributions}

SRLB designed and coordinated the study, wrote the report, collected the samples, performed laboratory testing, generated, analysed and interpreted data, searched the literature and produced the figures. CP designed and coordinated the study, wrote the report, analysed and interpreted data, and produced the figures. MNCK designed the study, performed laboratory testing, generated and interpreted data, searched the literature, and provided critical revision of the manuscript. HG designed the study, searched the literature, and provided critical revision of the manuscript (Qiagen was not involved in laboratory and statistical analyses and results were generated independently). RJL designed and coordinated the study, performed laboratory testing, generated and interpreted data, searched the literature, and provided critical revision of the manuscript. All authors read and approved the final manuscript.

\section{Acknowledgements}

We thank all women participating in our study. We would like to thank the Medical Mission Sisters and the medical staff at the Attat Hospital Ethiopia for allowing us to conduct this study and technically supporting us throughout. We acknowledge support by Deutsche Forschungsgemeinschaft and Open Access Publication Fund of University of Muenster for financing open access charges. digene Cervical Sampler were provided by Qiagen, Germany (formerly Digene). Qiagen was not involved in laboratory and statistical analyses and results were generated independently.

\section{Author details}

'Department of Gynecology and Obstetrics, University Hospital of Muenster, Muenster, Germany. ${ }^{2}$ Institute of Epidemiology and Social Medicine, University of Muenster, Muenster, Germany. ${ }^{3}$ INSERM, U970, Paris Cardiovascular Research Centre, University Paris Descartes, Sorbonne Paris Cité, Paris, France. ${ }^{4}$ DDL Diagnostic Laboratory, Rijswijk, The Netherlands. ${ }^{5}$ Department of Molecular Diagnostics Europe, QIAGEN GmbH, Hilden, Germany.

Received: 28 May 2014 Accepted: 16 September 2014 Published: 8 October 2014

\section{References}

1. Ferlay J, Soerjomataram I, Ervik M, Dikshit R, Eser S, Mathers C, Rebelo M Parkin DM, Forman D, Bray F: GLOBOCAN 2012 v1.0, Cancer Incidence and Mortality Worldwide: IARC CancerBase No. 11 [Internet]. International Agency for Research on Cancer: Lyon, France; 2013. Available from: http://globocan. iarc.fr, accessed on 01/12/2013.

2. WHO/ICO Information Centre on HPV and Cervical Cancer, (HPV Information (entre): Human Papillomavirus and Related Cancers in Ethiopia. Summary Report 2010. Available from: www.hpvcentre.net, accessed on 01/06/2011.

3. Munoz N, Castellsague X, de Gonzalez AB, Gissmann L: Chapter 1: HPV in the etiology of human cancer. Vaccine 2006, 24(Suppl 3):S3/1-10.

4. Kim JJ, Campos NG, O'Shea M, Diaz M, Mutyaba I: Model-based impact and cost-effectiveness of cervical cancer prevention in sub-Saharan Africa. Vaccine 2013, 31(Suppl 5):F60-F72.

5. Franceschi S, Herrero R, Clifford GM, Snijders PJ, Arslan A, Anh PT, Bosch FX, Ferreccio C, Hieu NT, Lazcano-Ponce E, Matos E, Molano M, Qiao YL, Rajkumar R, Ronco G, de Sanjose S, Shin HR, Sukvirach S, Thomas JO, Meijer CJ, Munoz N: Variations in the age-specific curves of human papillomavirus prevalence in women worldwide. Int J Cancer 2006, 119:2677-2684.

6. Li N, Franceschi S, Howell-Jones R, Snijders PJ, Clifford GM: Human papillomavirus type distribution in 30,848 invasive cervical cancers worldwide: Variation by geographical region, histological type and year of publication. Int J Cancer 2011, 128:927-935.

7. Markowitz LE, Hariri S, Unger ER, Saraiya M, Datta SD, Dunne EF: Postlicensure monitoring of HPV vaccine in the United States. Vaccine 2010, 28:4731-4737.

8. World Health Organization: Monitoring the coverage and impact of human papillomavirus vaccine - report of WHO meeting, November 2009. Wkly Epidemiol Rec 2010, 85:237-243.

9. Pospieschil A: Das Attat Hospital in Äthiopien. Charity-Page [Internet]. Available from: http://www.attat-hospital.de/, accessed on 01/01/2013.
10. Ruland R, Prugger C, Schiffer R, Regidor M, Lelle RJ: Prevalence of human papilloma virus infection in women in rural Ethiopia. Eur J Epidemio/ 2006, 21:727-729

11. Saiki RK, Gelfand DH, Stoffel S, Scharf SJ, Higuchi R, Horn GT, Mullis KB, Erlich HA: Primer-directed enzymatic amplification of DNA with a thermostable DNA polymerase. Science 1988, 239:487-491.

12. Geraets DT, Heideman DA, de Koning MN, Snijders PJ, Meijer CJ, van Doorn $L$, Quint WG: High genotyping concordance between the digene HPV genotyping $\mathrm{RH}$ test and the reverse line blot genotyping assay on GP5+/6 + -PCR products. J Clin Virol 2009, 46(Suppl 3):S16-S20.

13. Kleter B, van Doorn LJ, Schrauwen L, Molijn A, Sastrowijoto S, ter Schegget J, Lindeman J, ter Harmsel B, Burger M, Quint W: Development and clinical evaluation of a highly sensitive PCR-reverse hybridization line probe assay for detection and identification of anogenital human papillomavirus. J Clin Microbiol 1999, 37:2508-2517.

14. Doll R, Payne P, Waterhouse J: Cancer incidence in five continents: a technical report. International Union Against Cancer (IUAC). Berlin: Springer-Verlag; 1966.

15. Schiffman M, Herrero R, Desalle R, Hildesheim A, Wacholder S, Rodriguez AC, Bratti MC, Sherman ME, Morales J, Guillen D, Alfaro M, Hutchinson M, Wright TC, Solomon D, Chen Z, Schussler J, Castle PE, Burk RD: The carcinogenicity of human papillomavirus types reflects viral evolution. Virology 2005, 337:76-84.

16. Schellenbacher C, Roden R, Kirnbauer R: Chimeric L1-L2 virus-like particles as potential broad-spectrum human papillomavirus vaccines. J Virol 2009, 83:10085-10095.

17. Smith JS, Melendy A, Rana RK, Pimenta JM: Age-specific prevalence of infection with human papillomavirus in females: a global review. J Adolesc Health 2008, 43:S5-S25. S25 e21-41.

18. Gage JC, Ajenifuja KO, Wentzensen NA, Adepiti AC, Eklund C, Reilly M, Hutchinson M, Wacholder S, Harford J, Soliman AS, Burk RD, Schiffman M: The age-specific prevalence of human papillomavirus and risk of cytologic abnormalities in rural Nigeria: implications for screen-and-treat strategies. Int J Cancer 2012, 130:2111-2117.

19. Safaeian M, Kiduggavu M, Gravitt PE, Gange SJ, Ssekasanvu J, Muroka D, Sklar M, Serwada D, Wawer MJ, Shah KV, Gray R: Prevalence and risk factors for carcinogenic human papillomavirus infections in rural Rakai, Uganda. Sex Transm Infect 2008, 84:306-311.

20. Castellsague X, Menendez C, Loscertales MP, Kornegay JR, dos Santos F Gomez-Olive FX, Lloveras B, Abarca N, Vaz N, Barreto A, Bosch FX, Alonso P. Human papillomavirus genotypes in rural Mozambique. Lancet 2001, 358:1429-1430.

21. De Vuyst H, Clifford G, Li N, Franceschi S: HPV infection in Europe. Eur J Cancer 2009, 45:2632-2639.

22. de Sanjose S, Diaz M, Castellsague X, Clifford G, Bruni L, Munoz N, Bosch FX: Worldwide prevalence and genotype distribution of cervical human papillomavirus DNA in women with normal cytology: a meta-analysis. Lancet Infect Dis 2007, 7:453-459.

23. Castle PE, Schiffman M, Herrero R, Hildesheim A, Rodriguez AC, Bratti MC, Sherman ME, Wacholder S, Tarone R, Burk RD: A prospective study of age trends in cervical human papillomavirus acquisition and persistence in Guanacaste, Costa Rica. J Infect Dis 2005, 191:1808-1816.

24. Clarke MA, Gage JC, Ajenifuja KO, Wentzensen NA, Adepiti AC, Wacholder S, Burk RD, Schiffman M: A population-based cross-sectional study of age-specific risk factors for high risk human papillomavirus prevalence in rural Nigeria. Infect Agent Cancer 2011, 6:12

25. Bissett SL, Draper E, Myers RE, Godi A, Beddows S: Cross-neutralizing antibodies elicited by the Cervarix $(\mathrm{R})$ human papillomavirus vaccine display a range of Alpha-9 inter-type specificities. Vaccine 2014, 32:1139-1146.

26. Barzon L, Squarzon L, Masiero S, Pacenti M, Marcati G, Mantelli B, Gabrielli L, Lazzarotto T, Caputo A, Palu G: Neutralizing and cross-neutralizing antibody titres induced by bivalent and quadrivalent human papillomavirus vaccines in the target population of organized vaccination programmes. Vaccine 2014, 32:5357-5362.

27. Guan P, Howell-Jones R, Li N, Bruni L, de Sanjose S, Franceschi S, Clifford GM: Human papillomavirus types in 115,789 HPV-positive women: a meta-analysis from cervical infection to cancer. Int J Cancer 2012, 131:2349-2359.

28. Banura C, Mirembe FM, Orem J, Mbonye AK, Kasasa S, Mbidde EK: Prevalence, incidence and risk factors for anogenital warts in Sub Saharan Africa: a systematic review and meta analysis. Infect Agent Cancer 2013, 8:27. 
29. Dames DN, Ragin C, Griffith-Bowe A, Gomez P, Butler R: The prevalence of cervical cytology abnormalities and human papillomavirus in women infected with the human immunodeficiency virus. Infect Agent Cancer 2009, 4(1):S8.

30. Lazcano-Ponce E, Herrero R, Munoz N, Cruz A, Shah KV, Alonso P, Hernandez P, Salmeron J, Hernandez M: Epidemiology of HPV infection among Mexican women with normal cervical cytology. Int J Cancer 2001, 91:412-420.

31. Central Statistical Agency [Ethiopia]: Ethiopia Demographic and Health Survey 2005. Ethiopia and Calverton, Maryland, USA: Central Statistical Agency and ORC Macro Addis Ababa; 2006.

32. Vaccarella S, Herrero R, Dai M, Snijders PJ, Meijer CJ, Thomas JO, Hoang Anh PT, Ferreccio C, Matos E, Posso H, de Sanjose S, Shin HR, Sukvirach S, Lazcano-Ponce E, Ronco G, Rajkumar R, Qiao YL, Munoz N, Franceschi S: Reproductive factors, oral contraceptive use, and human papillomavirus infection: pooled analysis of the IARC HPV prevalence surveys. Cancer Epidemiol Biomarkers Prev 2006, 15:2148-2153.

33. Meijer CJ, Berkhof J, Castle PE, Hesselink AT, Franco EL, Ronco G, Arbyn M, Bosch FX, Cuzick J, Dillner J, Heideman DA, Snijders PJ: Guidelines for human papillomavirus DNA test requirements for primary cervical cancer screening in women 30 years and older. Int J Cancer 2009, 124:516-520.

34. Safaeian M, Herrero R, Hildesheim A, Quint W, Freer E, Van Doorn LJ, Porras C, Silva S, Gonzalez P, Bratti MC, Rodriguez AC, Castle P: Comparison of the SPF10-LiPA system to the hybrid capture 2 assay for detection of carcinogenic human papillomavirus genotypes among 5,683 young women in Guanacaste, Costa Rica. J Clin Microbiol 2007, 45:1447-1454.

35. Castle PE, Solomon D, Wheeler CM, Gravitt PE, Wacholder S, Schiffman M: Human papillomavirus genotype specificity of hybrid capture 2. J Clin Microbiol 2008, 46:2595-2604

36. de Cremoux P, Coste J, Sastre-Garau X, Thioux M, Bouillac C, Labbe S, Cartier I, Ziol M, Dosda A, Le Gales C, Molinie V, Vacher-Lavenu MC, Cochand-Priollet B, Vielh P, Magdelenat H: Efficiency of the hybrid capture 2 HPV DNA test in cervical cancer screening. A study by the French society of clinical cytology. Am J Clin Pathol 2003, 120:492-499.

37. Hesselink AT, Bulkmans NW, Berkhof J, Lorincz AT, Meijer CJ, Snijders PJ: Cross-sectional comparison of an automated hybrid capture 2 assay and the consensus GP5+/6+ PCR method in a population-based cervical screening program. J Clin Microbiol 2006, 44:3680-3685.

doi:10.1186/1750-9378-9-33

Cite this article as: Leyh-Bannurah et al.: Cervical human papillomavirus prevalence and genotype distribution among hybrid capture 2 positive women 15 to 64 years of age in the Gurage zone, rural Ethiopia. Infectious Agents and Cancer 2014 9:33.

\section{Submit your next manuscript to BioMed Central and take full advantage of:}

- Convenient online submission

- Thorough peer review

- No space constraints or color figure charges

- Immediate publication on acceptance

- Inclusion in PubMed, CAS, Scopus and Google Scholar

- Research which is freely available for redistribution 